\title{
Self-attribution of attitude as a function of belief feedback
}

\author{
CLYDE HENDRICK \\ Kent State University, Kent, Ohio 44242 \\ and \\ MARTIN GIESEN \\ Mississippi State University, State College, Mississippi 39762
}

\begin{abstract}
Previous research has found that subjects listening to a communication can be persuaded more when they receive false physiological feedback concerning their emotional state than when such feedback is not presented. Such results, in conjunction with Bem's (1972) postulate that subjects infer their attitude from the external circumstances of their behavior, suggested that false feedback of belief or disbelief would affect persuasion. Subjects listened to a speech while observing their (false) reactions on a "belief meter." Half of the subjects received strong positive belief feedback, and the other half received strong disbelief feedback. Demand characteristics were varied by telling half of the subjects in each group that the meter was highly reliable and valid and the other half that is was of questionable validity. Results showed that the meter feedback affected self-attributions of attitude. Subjects receiving disbelief feedback rated their attitude the same as a control group who merely completed the attitude scale. Subjects receiving belief feedback were persuaded more than a control group receiving only the communication. The implications of the data for the construct of attitude were discussed.
\end{abstract}

Much theorizing about attitudes assumes that an attitude is a latent variable with dynamic-directive properties (see Hendrick \& Seyfried, 1974, for a review). As a latent variable, the attitude consists of private stimuli (i.e., beliefs, feelings, etc.), and changing an at titude requires manipulation of variables which affect the private stimuli. During the last decade, this approach has come under increasing attack. Schachter and Singer (1962) showed that under some conditions manipulation of external situational cues resulted in widely varying self-descriptions by subjects of their emotional state. More recently, Bem (1972, p. 5) posed the issue with a basic assumption that "individuals come to 'know' their own attitudes, emotions, and other internal states partially by inferring them from observations of their own overt behavior and/or the circumstances in which this behavior occurs." However, an important qualification is that the inference process works best "to the extent that internal cues are weak, ambiguous, or uninterpretable,"

This research was supported by Grant MH 20388-01 from the National Institute of Mental Health. Requests for reprints should be addressed to Clyde Hendrick, Department of Psychology, Kent State University, Kent, Ohio 44242. The authors are indebted to Bret Harrison, Robert Lecate, and Jeffrey Liber for serving as experimenters. because under such conditions "the individual is functionally in the same position as an outside observer, an observer who must necessarily rely upon those same external cues to infer the individual's inner states" (Bem, 1972, p. 5). The qualification is important because, as will be seen in the present study, when subjects do have some internal evidence for their own attitudes, a nonsymmetry of the attribution process occurs, relative to conditions in which internal evidence is weaker.

Bem's approach denies (in a weak form) that an attitude has dynamic properties. Rather, an attitude is "created" which an individual "knows" each time the individual observes his own behavior under given conditions. When conditions change, a new attitude may be observed and, further, the individual need not be aware of any so-called process of attitude change (Bem \& McConnell, 1970). The Bemian approach is basically an "inside" to "outside" metaphor reversal. For example, in the classical approach the lie detector is supposed to ferret out and reveal one's true inner feelings. With Bem, one looks at the tracings of the lie detector to infer what one's true feelings must be.

If external circumstances do exert some control over the self-attributions called attitudes, it ought to be possible, following the metaphor reversal, to 
affect . subjects' attitude descriptions by boldly telling them what their beliefs are. An external device which tells a subject what he believes may be dubbed a "belief meter." The present research was concerned with whether such a belief meter could (with suitable controls for demand characteristics) affect the subjects' attitude on an issue.

The technique used involved presenting false feedback on a meter device in which the meter readings were represented to subjects as a measure of their belief state. False feedback of one attribute or another has been used effectively in several studies. Harris and Jellison (1971) found that false physiological feedback of high fear arousal which was subsequently reduced led to greate persuasion than other combinations of false feedback. Giesen and Hendrick (1974) found that high feedback, regardless of the emotional label (e.g., pleasantness, unpleasantness, fear), led to greater persuasion than low feedback. If subjects received feedback during a communication that they were highly emotional, they were more persuaded regardless of the label of the emotional arousal. Giesen and Hendrick (1974) suggested that subjects who received high arousal feedback may have treated a cognition "I am emotional" as equivalent to "I believe that." If so, comparable manipulation of attitude should be obtained by labeling directly the false feedback as either "strong belief" or "strong disbelief."

Similar results were also obtained by Hendrick, Giesen, and Borden (1975), who found that high feedback of fear arousal enhanced persuasion, and that the persuasive effect was independent of whether or not the arousal was reduced during the communication.

In the present experiment, subjects listened to a brief speech while observing a meter purportedly giving feedback about their belief reactions. Half of the subjects observed a strong belief reaction to the speech, while the other half observed a strong disbelief reaction. It was predicted that subjects in the belief condition would manifest a more positive attitude in the advocated direction than subjects in the disbelief condition. Since such an outcome could be due to demand characteristics, an additional manipulation was used in which half of the subjects were told that the belief meter was a highly reliable and valid device. The other half of the subjects were told that the belief meter was of questionable reliability and validity.

The concept of the belief meter as used in the present study was a relatively novel use of the false feedback procedure. However, a relevant study was reported by Ross, Insko, and Ross (1971). In the Ross et al. study, some subjects observed "agree" or "disagree" responses to an item on a questionnaire they had completed earlier in the quarter. In fact, the item was bogus and had not appeared on the earlier questionnaire. Subjects were randomly assigned to "agree" or "disagree" positions. When these subjects later completed an attitude scale on the issue, their responses closely matched the "agree" or "disagree" position to which they had been assigned. Although there is some possibility that the Ross et al. results might have been due to demand characteristics, their results at least suggest that the predictions for the belief meter in the present study are conceptually viable.

Finally, the belief meter feedback procedure should not be confused with the bogus pipeline procedure introduced by Jones and Sigall (1971). The belief meter is part of a long tradition of research which uses false feedback as a technique for manipulating an independent variable. However, Jones and Sigall (1971. p. 354) specifically identified the bogus pipeline as a dependent variable paradigm, because the subject guesses what the (unseen) machine is measuring physiologically on some specified dimension of interest.

\section{METHOD}

\section{Overview and Design}

Subjects listened to a taped speech on pesticides under the guise of participating in a study of communication evaluation. The speech (about $4 \mathrm{~min}$ long) was the same as Part 1 of the speech used by Harris and Jellison (1971). The speech discussed several current problems in the use of pesticides. While listening to the information, subjects received false feedback concerning their "objective belief reaction," which was either strong belief or strong disbelief. Prior to listening to the speech, subjects received information that the meter was either highly valid or of questionable validity. Thus, there were four basic experimental conditions constituting a 2 by 2 factorial design: belief-valid meter, belief-invalid meter, disbelief-valid meter, and disbelief-invalid meter. The basic design was replicated by three undergraduate male experimenters who constituted a third independent variable. Rating measures of belief on the topic and checks on the manipulations were completed immediately after listening to the speech.

Two additional control conditions were used. In a communication-only condition, subjects listened to the speech without the false feedback device. An "unexposed control" group merely completed the belief portion of the questionnaire.

\section{Subjects}

There were 108 female students from an introductory psychology class who served as subjects in the meter feedback conditions. Subjects participated two or three at a time in separate cubicles. Twenty-seven subjects were randomly assigned to each of the four basic conditions, with each experimenter collecting data from nine subjects per condition. Ten subjects were replaced or discarded, five because of suspicion of the meter, two because of incomplete questionnaires, and three (randomly) to equalize the number of subjects in each condition.

There were 41 students who served as subjects in the communication-only control condition. Those subjects, who served in one large group, heard part of the cover story on communication evaluation, listened to the speech, and then completed the relevant part of the questionnaire. Finally. 36 subjects served in the unexposed control condition. These subjects completed only the belief and attitude questions on the rating form.

\section{Apparatus}

The basic equipment from the subject's perspective was a device which consisted of a meter dial built into a brown wooden instrument box. The device had a small signal light 
mounted on top above the meter, an on-off switch, and two small jacks with wires leading to electrodes which were attached to two fingers of the subject's nonpreferred hand. The subject was told that the apparatus registered objective belief reactions to information, picked up via the finger electrodes. A sign "objective belief reactions" was mounted in a prominent position on the panel just above the meter dial. The meter dial was divided into three ranges labeled strong belief, neutral belief, and strong disbelief. One track of a stereo tape controlled the belief feedback and coordinated it to the speech which was recorded on the second track of the same tape. Two basic versions of the tape were prepared, one with belief readings and the second with disbelief readings.

\section{Procedure}

Once the subject was seated in the cubicle facing the belief meter, taped instructions were played which presented the cover story and the manipulation of validity-invalidity of the meter. The cover story stated that the experiment was concerned with various aspects of communication evaluation. Subjects' attention was directed to the meter and finger electrodes. They were told to think of the meter as similar to a lie detector but that, instead of reactions to questions as in a lie detector, the meter "measures the degree to which you tend to believe or disbelieve information presented in a communication." Further information about psychophysical measurement of bodily states was enumerated, reinforcing the conclusion that physiological reactions to information could be translated into belief-disbelief reactions on the meter. A distinction was drawn between "objective" and "subjective" belief reactions in order to minimize any suspicions that might arise because of a discrepancy between phenomenal feelings and the false feedback. The meter function was summarized as providing a fairly direct and immediate measure of the belief reaction.

At this point in the instructions, a manipulation of the efficacy of the meter was introduced in order to actively manipulate the demand characteristics associated with the experimental situation. Subjects receiving valid meter instructions were told that previous research had shown the meter to be an extremely reliable and valid measure of how much one believes or disbelieves information and that the purpose of the present study was to extend knowledge of belief reactions to different kinds of communications. Subjects receiving invalid meter instructions were told that previous research with the meter had not produced clear-cut results and that the reliability and validity of the instrument in measuring belief reactions was questionable. The purpose of the present study was to continue basic research in order to determine just how good the meter really was.

Subjects were asked to record their own belief reactions since "automatic recording equipment was not available." This procedure insured that subjects appropriately perceived their belief feedback. Each subject recorded her belief level as either belief, neutral belief, or disbelief at 15-sec intervals on a "time sampling sheet" during the communication. The experimenter controlled the time intervals which were signaled by the lamp on top of the meter. About midway through the instructions, the experimenter distributed the time sampling sheets, assigned subject numbers, and asked subjects to write "On Pesticides" at the top of the sheet. The instructions continued, explaining in detail how to use the sheets and preparing subjects for the ratings to be made at the end of the communication.

After the instructions ended, the experimenter randomly selected a belief or disbelief treatment, put the appropriate tape on the recorder, attached the finger electrodes, and answered any procedural questions before starting the tape. The communication tapes were designed so that the meter fluctuations were activated in the neutral range during the first minute of the tape. During the final $3 \mathrm{~min}$ of the speech, the meter needle progressed into the belief or disbelief regions and fluctuated within the respective range, showing either strong belief or strong disbelief reactions by the end of the speech.

After the speech ended, the experimenter asked the subjects to reach up and switch off their meters and then to total the number of checkmarks in each of the belief, neutral, and disbelief columns of their time sampling sheet. Next they were asked to complete a "subjective belief index" which was actually the dependent variable and checks on the manipulation. Upon completion of the rating forms, subjects were asked to write their comments on the back of the forms. They were then questioned briefly concerning their reactions to the experiment, debriefed, sworn to silence, and dismissed.

\section{Questionnaire Measures}

The subjective belief index consisted of 30 items. The first 14 items were belief statements, each containing a scale of 30 dots with ends labeled "completely true" and "completely false." The first two items were "Insecticides contaminate foodstuffs on a large scale" and "Many people have died from insecticide poisoning." Responses were scored from 1 to 30 for each item, and a sum score for the 14 items was derived which could range from 14 to 420 .

The remaining items were rated on 9-point numerical scales with appropriate end labels. Three of these items were considered as attitude statements (similar to the belief statements), but the end labels were strongly agree and strongly disagree. Two items assessed fear and anxiety felt during the communication, two items asked how interesting and enjoyable the speech was, two items assessed the credibility of the speaker, and several items were concerned with subjects' causal attributions concerning their belief reactions. Finally, two items served as checks on the manipulation of meter validity-invalidity

\section{RESULTS}

Each of the rating measures was subjected to a threeway analysis of variance. There were very few effects due to experimenters and this variable will be ignored for economy in presentation of the data. The results are presented for manipulation checks, belief scores, and secondary rating measures.

\section{Manipulation Checks}

Two questions served as manipulation checks. The first question was "How reliable and valid did the experimenter say the meter is in registering belief reactions?" Only the main effect of valid-invalid instructions was significant for this question $[F(1,96)=$ $66.6, \mathrm{p}<.0001]$ and none of the other effects approached significance. The mean for the valid condition was 7.3 (with 9.0 possible), and for the invalid condition 3.9 (the standard error of the means, SE, for the comparison was .29). Clearly, the subjects adequately discriminated the manipulation.

The second check question asked "How reliable and valid do you believe the meter is in registering belief reactions?" For this item the valid-invalid main effect was not significant $(F=2.8)$. Only the main effect of belief-disbelief was significant $[F(1,96)=16.7, p<$ $.0003]$. Subjects in the belief condition had more confidence in the meter $(5.5)$ than subjects in the disbelief 
Table 1

Mean Belief Scores

\begin{tabular}{llc}
\hline & \multicolumn{2}{c}{ Meter } \\
& Belief & $\begin{array}{c}\text { Feedback } \\
\text { Disbelief }\end{array}$ \\
\hline Validity Condition & & \\
$\quad$ Valid Meter & 300.4 & 244.2 \\
$\quad$ Invalid Meter & 314.2 & 252.9 \\
$\quad$ Mean & 307.3 & 248.6 \\
Control Groups & & \\
$\quad$ Communication Only & 283.7 & \\
$\quad$ Unexposed Control & 252.9 \\
\hline
\end{tabular}

condition (3.8). The SE was .30. This result is peculiar and interesting. As noted in the following sections, subjects were initially in moderate agreement with the position advocated by the speech. Thus, subjects in the disbelief condition received feedback which was contrary to their initial belief. Consequently, to some extent they probably discredited the meter. However, as will be shown, the results for persuasion were opposite to what would be expected if such discredit were causally related to attitudinal acceptance.

\section{Belief Scores}

The means for the belief scores are shown in Table 1 for the four experimental conditions and the two control groups. The higher the score, the more agreement with the position advocated in the speech. Within the factorial design, the only significant effect was belief-disbelief $[F(1,96)=24.8, p<.0001]$. The SE for the belief-disbelief effect was 8.3 . Subjects in the belief condition agreed with the speech more (307.3) than subjects in the disbelief condition (248.6). In fact, subjects in the disbelief condition had a slightly lower mean than unexposed control subjects (252.9).

In order to make comparisons more precisely, a one-way analysis of variance was computed with the belief, disbelief, communication-only, and unexposed controls considered as four levels of a single variable. The main effect was significant $[F(3,181)=9.5$, $\mathrm{p}<.001]$. Newman-Keuls comparisons for unequal number of subjects (Winer, 1971, p. 216) yielded the following results. (a) The mean for the communicationonly condition (283.7) was significantly greater than the unexposed control mean (252.9), indicating that the communication per se had a persuasive effect. (b) The unexposed control mean was significantly lower than the belief mean (307.3). (c) The unexposed control mean was not significantly different from the disbelief mean. (d) The belief and disbelief means differed significantly. (e) The disbelief mean (248.6) was significantly lower than the communication-only mean (283.7). (f) Finally, the belief mean (307.3) just missed being significantly larger than the communication-only mean (283.7); a mean difference of 25.1 was required for significance at the .05 level, and the actual difference was 23.6.

These results demonstrate the substantial effect that the meter feedback had on'self-attributions of attitude. Positive belief feedback enhanced attitudinal acceptance somewhat above that provided by the communication alone (just short of significance). More dramatically, disbelief feedback completely nullified the persuasive effect of the message and, in fact, significantly reduced attitudinal acceptance below that provided by the communication alone. As noted in the previous section, subjects in the disbelief condition rated the meter quite low in reliability and validity. Yet, the meter exerted strong control over their self-attributions of attitude. Such a low belief mean (248.6) would not be expected if the low reliability-validity ratings were causally related to self-attribution of attitude.

The results noted above were further confirmed by an analysis of the sum scores of the three attitude items in the questionnaire. It will be recalled that these items differed from belief items in having strongly agree-disagree end labels rather than true-false end labels. Scores could range from 3 to 27 for this measure. The only significant effect was a belief-disbelief main effect $[F(1,96)=6.2$, $p<.02]$. The mean score for the belief condition was 21.5 , but only 19.3 for the disbelief condition $(\mathrm{SE}=.62)$. Thus, both belief statements and attitude items yielded comparable results.

\section{Secondary Results}

Most of these measures were included to clarify results for the dependent variable or to test possible alternative interpretations of the data. For example, one condition might be more interesting than another, leading to greater persuasion. However, there were no significant effects for the items "How interesting was the communication" and "How enjoyable was the communication." Also, the item "How anxious were you during the communication" did not yield any significant results.

However, several items did yield consistent main effects for the belief-disbelief manipulation. These items, means, and $F$ ratios are shown in Table 2. As indicated, subjects in the disbelief condition were more fearful, trusted the speaker less and felt he was less reliable, felt their belief reactions were not as much due to the speech, and rated their subjective beliefs as less similar to the meter than subjects in the belief condition. This pattern of results indicates that subjects in the disbelief condition had more difficulty in accepting the meter-induced attribution. They expressed more fear and tended to derogate the speaker. Since the belief mean for the unexposed control group was a moderately positive 252.9 (with 210.0 as the theoretical neutral point), it seems likely that subjects in the disbelief condition were aware of the discrepancy between what the meter told them their feelings were and what they in fact thought they were. This discrepancy led to puzzlement and perhaps some hostility. 
Table 2

Belief-Disbelief Means for Secondary Measures

\begin{tabular}{|c|c|c|c|c|}
\hline \multirow[b]{2}{*}{ Item } & \multicolumn{4}{|c|}{ Meter Feedback } \\
\hline & Belief & Disbelief & F Ratio & $\mathrm{SE}^{* *}$ \\
\hline \multirow{3}{*}{$\begin{array}{l}\text { How fearful did you feel during the communication. } \\
\text { I trust the speaker to tell the truth about the topic. } \\
\text { The speaker is a reliable source of information } \\
\text { on the topic. }\end{array}$} & 2.1 & 3.2 & $10.7^{*}$ & .24 \\
\hline & 6.8 & 5.4 & $13.9^{*}$ & .26 \\
\hline & 5.9 & 4.8 & $10.1^{*}$ & .26 \\
\hline $\begin{array}{l}\text { To what extent were your belief reactions } \\
\text { caused by the speaker. }\end{array}$ & 6.5 & 3.8 & $58.8^{*}$ & .25 \\
\hline $\begin{array}{l}\text { How similar were your own subjective beliefs to your } \\
\text { beliefs as physiologically registered by the meter. }\end{array}$ & 6.5 & 4.0 & $40.0^{*}$ & .29 \\
\hline
\end{tabular}

\section{DISCUSSION}

The results of the experiment demonstrated quite clearly the strong stimulus control the meter had over the subjects' expression of belief and attitude. When the meter said subjects believed, they had a very high belief score. When the meter said the subjects disbelieved, the belief score was even slightly lower than that of an unexposed control group. The metaphor reversal of the Bemian approach was not complete, however. Subjects' attitudes were not "created" by the meter, since subjects in the disbelief condition apparently were aware of the discrepancy between the feedback and their own inner feelings. It would be more accurate to say that the belief meter functioned as a booster, providing a positive increment in the belief condition and a decrement in the disbelief condition, but the decrement incurred certain costs such as the derogation of the communicator.

One possible alternative is that subjects in the disbelief condition simply "went along" with the experimenter expressing low belief and attitude scores. This alternative has low plausibility. It true, one would expect a significant belief-disbelief by valid-invalid meter interaction in the belief scores. However, no such interaction occurred. Further, there is no reason to expect that subjects would simply "go along" on the numerous dependent belief and attitude measures when they clearly did not give cooperative responses on the secondary measures shown in Table 2. Thus, this version of the demand characteristics argument fails to account for the data.

Actually, the various results readily bring to mind Leventhal's (1970) parallel response model. According to the model, a (fear) communication may cue off responses of fear, persuasion, and behavioral intentions with the response systems operating in parallel channels but without necessary causal interconnections. In the present experiment, the meter feedback may have served as a strong communication which cued off several reactions, including various degrees of persuasive acceptance, perceptions of speaker credibility, congruence of feedback with self-feelings, etc.
These various reactions appeared to be parallel but noncausally related consequences of the meter feedback.

It is worth reiterating the striking behavioral control that the meter exerted over belief and attitude reactions. To a certain extent, the results support Bem's contention that individuals infer their attitudes from observation of their own behavior and its controlling circumstances. For those of us who tend to view an attitude as a latent variable, an interesting question would be whether attitudes shaped by a belief meter will in turn affect behavior in later situations (e.g., obtaining petition signatures against pesticides). If such later behaviors are affected, it would seem that a more balanced view of the attitude concept is required. It must be granted from the present data that attitudes can to an extent be shaped in Machiavellian fashion by simply telling people what they believe. However, once people "know" what they believe, they can and do act on those beliefs. In this sense, an attitude is a latent determinative variable. The balanced approach, then, conceives of an attitude as both an internal latent variable and an external inference about the outside world.

\section{REFERENCES}

BEM, D. J. Self-perception theory. In L. Berkowitz (Ed.), Advances in experimental social psychology. Vol. 6. New York: Academic Press. 1972.

Bem, D. J., \& McConnell, H. K. Testing the self-perception explanation of dissonance phenomena: On the salience of premanipulation attitudes. Journal of Personality and Social Psychology, 1970, 14, 23-31.

Giesen, M., \& Hendrick, C. Effects of false positive and negative arousal feedback on persuasion. Joumal of Personality and Social Psychology, 1974, 30, 449-457.

HARRIS, V. A., \& Jellison, J. M. Fear-arousing communications, false physiological feedback, and the acceptance of recommen. dations. Journal of Experimental Social Psychology, 1971. 7. 269-279.

Hendrick, C., Giesen, M., \& Borden, R. False physiological feedback and persuasion: Effect of fear arousal vs. fear reduction on attitude change. Joumal of Personality, 1975, 43, 196-214.

Hendrick. C., \& SEyfried, B. Assessing the validity of laboratory-produced attitude change. Joumal of Personality and Social Psychology, 1974, 29, 865-870. 
Jones, E. E., \& Sigall, H. The bogus pipeline: A new paradigm for measuring affect and attitude. Psychological Bulletin, 1971, 76, 349-364.

LeVenthal, $H$. Findings and theory in the study of fear communications. In L. Berkowitz (Ed.), Advances in experimental social psychology. Vol. 5. New York: Academic Press, 1970.

Ross, M., Insko, C. A., \& Ross, H. S. Self-attribution of attitude. Journal of Personality and Social Psychology. 1971, 17, 292-297.
Schachter. S., \& Singer, J. E. Cognitive, social. and physiological determinants of emotional state. Psychological Review, 1962, 69, 379-399.

WINER. B. J. Statistical principles in experimental design. New York: McGraw-Hill, 1971.

(Received for publication May 7. 1975; revision received June 12.1975 . accepted June 18, 1975.) 